\title{
Stage-related variation in rapid cold hardening as a test of the environmental predictability hypothesis
}

\author{
John S. Terblanche*, Elrike Marais, Steven L. Chown \\ Centre for Invasion Biology, Department of Botany and Zoology, Stellenbosch University, Stellenbosch, South Africa
}

Received 28 November 2006; received in revised form 19 January 2007; accepted 23 January 2007

\begin{abstract}
The environmental predictability (EP) hypothesis proposes that rapid cold hardening $(\mathrm{RCH})$ might be common in temperate species incapable of surviving freezing events and which also dwell in unpredictable environments. The kelp fly Paractora dreuxi serves as a useful model organism to test this prediction at an intra-specific level because larvae and adults show different responses to low temperature despite occupying a similar unpredictable thermal environment. Here, using acclimation temperatures, which simulated seasonal temperature variation, we find little evidence for $\mathrm{RCH}$ in the freeze-intolerant adults but a limited $\mathrm{RCH}$ response in freezetolerant larvae. In the relatively short-lived adults, survival of $-11^{\circ} \mathrm{C}$ generally did not improve after $2 \mathrm{~h}$ pre-treatments at $-4,-2,0,10$, 20 or $25^{\circ} \mathrm{C}$ either in summer- $\left(10^{\circ} \mathrm{C}\right)$ or winter $\left(0^{\circ} \mathrm{C}\right)$-acclimated individuals. By contrast, survival of summer-acclimated larvae to $-7.6^{\circ} \mathrm{C}$ was significantly improved by $\sim 37 \%$ and $30 \%$ with -2 and $0{ }^{\circ} \mathrm{C}$ pre-treatments, respectively. The finding that summeracclimated larvae showed $\mathrm{RCH}$ whereas this was not the case in the winter-acclimated larvae partially supports the predictions of the EP hypothesis. However, the EP hypothesis also predicts that the adults should have demonstrated an RCH response, yet they did not do so. Rather, it seems likely that they avoid stressful environments by behavioural thermoregulation. Differences in responses among the adults and larvae are therefore to some extent predictable from differences in their feeding requirements and behaviour. These results show that further studies of $\mathrm{RCH}$ should take into account the way in which differences among life stages influence the interaction between phenotypic plasticity and environmental variability and predictability.
\end{abstract}

(C) 2007 Elsevier Ltd. All rights reserved.

Keywords: Lethal limits; Intra-population variation; Phenotypic plasticity; Predictability; Seasonal variation; Temporal variation

\section{Introduction}

Rapid cold hardening $(\mathrm{RCH})$ is a physiological mechanism which enables an organism to survive an otherwise lethal low temperature following pre-exposure to a less severe low temperature (Lee et al., 1987; Chen et al., 1987a). The RCH response is frequently accompanied by an immediate increase in glycerol and, on termination of the cold pre-treatment, often elicits heat shock protein production. RCH may also increase cell membrane fluidity (Lee et al., 2006a), probably through changes in polyunsaturated fatty acid composition (Overgaard et al., 2005), which enhance cellular survival at low temperatures (Lee et al., 2006a, b). Some or all of these biochemical

\footnotetext{
${ }^{*}$ Corresponding author. Tel.: + 2721808 2605; fax: + 27218082405 .

E-mail address: jst@sun.ac.za (J.S. Terblanche).
}

changes contribute to a reduction in the cellular damage typically associated with low-temperature stress (Denlinger and Lee, 1998; Lee et al., 2006b). Not only can RCH protect against non-freezing injury, but it may also increase freeze tolerance (Lee et al., 2006b). Consequently, RCH is now considered an important component of the suite of responses terrestrial invertebrates possess for coping with environmental temperature variation (Bale, 2002; Sinclair et al., 2003a, b; Lee et al., 2006b).

However, how extensive RCH is in insects, and whether any consistent environment-related pattern characterizes the expression of $\mathrm{RCH}$ is poorly understood (Chown and Nicolson, 2004). At present, approximately 30 terrestrial arthropod species are known to show RCH (Danks, 2005). By contrast, only a handful of species are unable to produce a cold-induced RCH response (e.g. Vandyk et al., 1996; Burks and Hagstrom, 1999; Sinclair and Chown, 
2003; Hawes et al., 2006). Nonetheless, it has been suggested that $\mathrm{RCH}$ provides a mechanism enabling activity despite sudden low-temperature periods, and that it might be advantageous when temperatures are unpredictable, such as in spring and autumn (Rosales et al., 1994; Kelty and Lee, 2001).

Sinclair and Chown (2005) took this idea several steps further when they suggested, on the basis of the literature and their work on temperate African species, that $\mathrm{RCH}$ might be common in temperate species incapable of surviving freezing events and which also dwell in unpredictable environments. This may be termed the 'environmental predictability (EP) hypothesis'. Such environments, which seem to be especially characteristic of the temperate to high latitudes of the southern hemisphere (Vasseur and Yodzis, 2004; Chown et al., 2004), are thought to promote strategies, including moderate freezing tolerance and $\mathrm{RCH}$ in individuals which are not freezing tolerant, that enable insects to cope with unexpected low-temperature periods (Sinclair et al., 2003a, b; see also van der Laak, 1982; Chen et al., 1990). In particular, individuals that are not freezing tolerant are thought to show $\mathrm{RCH}$ because they have no other physiological means of overcoming the otherwise lethal effects of a low-temperature stress.

However, the generality of this 'environmental predictability hypothesis' remains unresolved given that investigations of $\mathrm{RCH}$ in insects, and particularly southern hemisphere species, are still relatively uncommon. Moreover, substantial differences in response exist between the southern hemisphere species that have been investigated. In keeping with the EP hypothesis, two beetle species incapable of tolerating freezing, Chirodica chalcoptera and Afrinus sp., show considerable $\mathrm{RCH}$ in response to low-temperature pre-treatments, and the freezing-tolerant caterpillars of the moth Pringleophaga marioni do not (Sinclair and Chown, 2003, 2006; Terblanche et al., 2005). By contrast, in the Antarctic midge, Belgica antarctica, summer-acclimatized larvae show $\mathrm{RCH}$, while adults do not (Lee et al., 2006b). In addition, in cold-acclimated larvae freezing tolerance is improved by a low-temperature pre-treatment. Clearly, there is considerable variation in $\mathrm{RCH}$ responses between life stages, species and hemispheres, and there may also be some phylogenetic signal to the pattern, although insufficient evidence exists either way.

Clearly, further tests of the EP hypothesis require additional information either on (i) many species from a range of environments and encompassing the suite of responses to low temperature, (ii) species whose individuals differ substantially in their cold hardiness strategies (e.g. as a consequence of ontogeny) or (iii) on clades where species are exposed to different levels of environmental predictability (see Deere and Chown, 2006). An explicit prediction of the EP hypothesis is the absence of $\mathrm{RCH}$ in freezingtolerant individuals, and its presence in individuals that lack this suite of traits either permanently or as a temporary condition, such as is found in summer-acclimatized individuals of many temperate species (Zachariassen,
1985; Leather et al., 1993). The flightless sub-Antarctic kelp fly, Paractora dreuxi, provides a model species with which to pursue the second approach. Individuals switch from moderate freezing tolerance in the larval stage to chill susceptibility in adulthood (Klok and Chown, 2001), despite the fact that these stages occupy very similar thermal environments. Both inhabit and feed on decomposing kelp wrack, although the adults are less tightly associated with kelp fronds than are the larvae (Crafford and Scholtz, 1987).

Therefore, in this study we use $P$. dreuxi for a withinspecies test of the EP hypothesis. Specifically, we determine whether RCH is present in adults but not larvae, as the EP hypothesis indicates, and whether acclimation to simulated winter and summer conditions has an influence on $\mathrm{RCH}$ ability (see Lee et al., 2006b). We also determine whether high-temperature pre-treatments induce a change in lowtemperature survival. Several other studies have demonstrated that this can be the case and have used such assessments to gain insight into the mechanisms likely underlying RCH (Chen et al., 1991; Sinclair and Chown, 2003, 2006). Moreover, such assessments also provide information on the extent and nature of cross-tolerance, which in turn can provide significant insights into the mechanisms underlying, and the evolution of, responses to the abiotic environment (Chown and Nicolson, 2004; Pörtner, 2001).

\section{Materials and methods}

\subsection{Study site and acclimation of animals}

Paractora dreuxi (Diptera, Helcomyzidae) larvae and adults were collected using soft tweezers or aspirators, respectively, from Trypot Beach on sub-Antarctic Marion Island $\left(46^{\prime} 54^{\prime \prime} \mathrm{S} ; 37^{\prime} 45^{\prime \prime}{ }^{\circ} \mathrm{E}\right)$. Larvae and adults inhabit stony beaches year-round (Crafford et al., 1986), and are capable of vertical movement through the round stony substrate (Crafford, 1984). The larval stage takes approximately 2 months, with the third instar lasting 40-50 days and being responsible for most kelp consumption. The pupal stage lasts for 30-60 days, and the adults can live for 14-21 days (Crafford, 1984) feeding on decomposing kelp slime. Adults and larvae usually avoid the intertidal zone but can be found occasionally in the splash zone (upper eulittoral zone), 3-7 $\mathrm{m}$ from the shoreline (Crafford and Scholtz, 1987). They are very rarely found in terrestrial vegetation, but rather keep to the stony areas of the beach.

\subsection{Acclimations}

The study was conducted in April 2005 during the austral autumn. Live specimens were returned to the laboratory, where they were immediately sorted for acclimations or for experimental use (usually $<2 \mathrm{~h}$ postcapture). In the laboratory, the animals were kept in temperature-controlled cabinets at 0 or $10{ }^{\circ} \mathrm{C}$ (recorded 
mean \pm SD temperatures (using Thermochron DS1921 iButtons, Dallas Semiconductors, Texas): $0 \pm 0.7^{\circ} \mathrm{C}$ and $9.3 \pm 0.5^{\circ} \mathrm{C}$ ) with a photoperiod set to match environmental day light cycles at this time of the year (12:12 L:D) for a period of 7 days. They were housed in $500 \mathrm{ml}$ plastic jars at low density (adults: $n=25$ per container; larvae: $n=50$ per container) with moistened, fresh kelp. Kelp was replaced or added, moistened with fresh water, and containers were randomized between shelves on a daily basis. The 'acclimation temperatures' were chosen to represent summer and winter temperatures on Marion Island (for detailed microclimate data at sea level see Deere et al., 2006), but did not include the photoperiodic component to simplify interpretation of the effects. Seven days was selected as the acclimation period because previous work on other species both from Marion Island and elsewhere has indicated that acclimation responses equilibrate within this period (Hoffmann and Watson, 1993; Klok and Chown, 2003; Terblanche et al., 2006). A total of 200 adults and 200 larvae were exposed to each temperature.

\subsection{Determination of test temperature}

Although lower lethal temperatures have been determined previously using a slow cooling, ramping technique for $P$. dreuxi (Klok and Chown, 2001), we used a 'plunge' method similar to that of other RCH studies (e.g. Lee et al., 1987; Kelty and Lee, 2001; Sinclair and Chown, 2003). To determine which test temperature would induce low (but not zero) survival, we sorted field-collected adults and larvae into $60-\mathrm{ml}$ polypropylene tubes in groups of 8-10 individuals. Groups were plunged into a water bath (Grant LTC 12, Grant Instruments, UK) for $2 \mathrm{~h}$ at the set temperatures from -2 to $-14^{\circ} \mathrm{C}$ and -2 to $-9^{\circ} \mathrm{C}$ for adults and larvae, respectively ( $\left({ }^{\circ} \mathrm{C}\right.$ increments). Survival, defined as co-ordinated movement and response to a stimulus, was assessed after $24 \mathrm{~h}$ at $10^{\circ} \mathrm{C}$. This was replicated three times per temperature group. Discriminating temperatures of -7.6 and $-11.0^{\circ} \mathrm{C}$ were used for larvae and adults, respectively, based on replicated logistic regression of survival curves and interpolations of the temperatures at which $25 \%$ of the sample survived (Fig. 1). Klok and Chown (2001) previously demonstrated that in field-fresh animals collected at the same time of year, adults freeze from -6.7 to $-15^{\circ} \mathrm{C}$, but show some pre-freeze mortality, while larvae freeze at -3.1 to $-3.9^{\circ} \mathrm{C}$.

\subsection{Pre-treatment and handling controls}

Larvae and adults were taken from the incubators and placed into polypropylene tubes. Tubes were placed either into a water bath $\left(-4,-2{ }^{\circ} \mathrm{C}\right.$ treatments $)$ or a temperature-controlled chamber $\left(0,10,20,25^{\circ} \mathrm{C}\right.$ treatments). After $2 \mathrm{~h}$, tubes were removed and placed into a water bath set to the discriminating temperatures of -7.6 or $-11.0^{\circ} \mathrm{C}$ for larvae and adults, respectively. After $2 \mathrm{~h}$ at
A

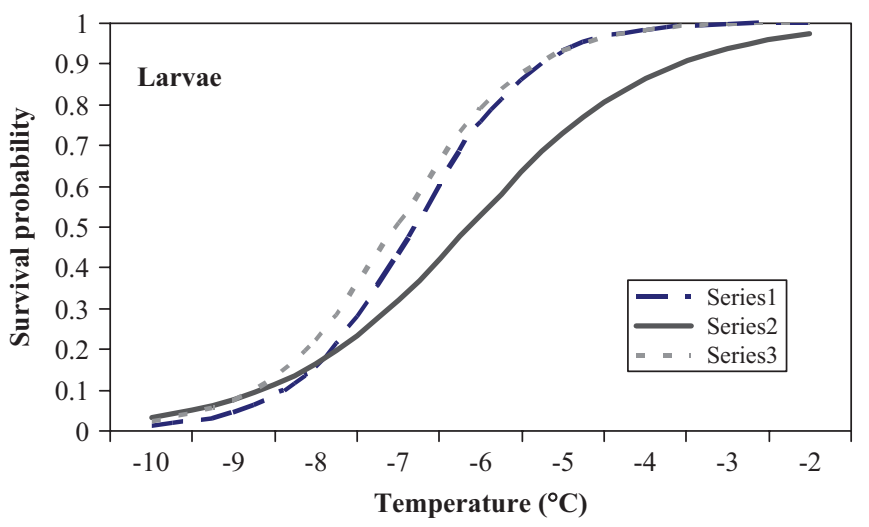

B

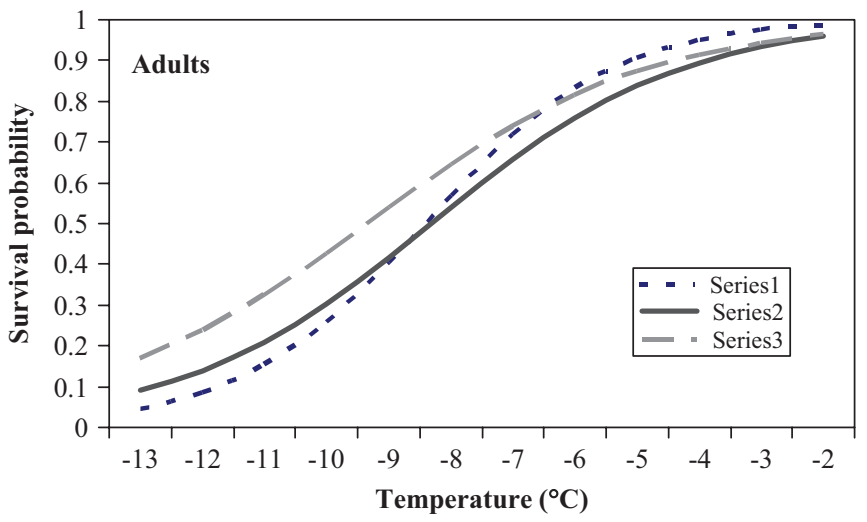

Fig. 1. Replicated lower lethal temperature curves derived from probability functions in (A) larvae and (B) adults of Paractora dreuxi. No pretreatments were used during the determination of lower lethal temperatures.

the discriminating temperature, tubes were removed from water baths or climate chamber treatments and transferred back to their original acclimation temperatures and survival was scored after $24 \mathrm{~h}$. A replicated 'handling control' was included in each acclimation group and involved plunging tubes $(n=3)$ into a water bath set to 0 or $10^{\circ} \mathrm{C}$ as appropriate. The handling controls were removed after $2 \mathrm{~h}$ and placed at either 0 or $10^{\circ} \mathrm{C}$ in temperature-controlled chambers for the 0 and $10^{\circ} \mathrm{C}$ acclimations, respectively, for recovery $(24 \mathrm{~h})$ and subsequent scoring of survival. The order of pre-treatments was randomized during experimental days. The complete set of raw survival data is available from the corresponding author upon request.

\subsection{Statistical analyses}

Lower lethal temperature curves were obtained using PROC PROBIT in SAS (v. 9.0, SAS Institute, Cary, NC, USA) for each replicate. Initially, generalized linear model analyses were undertaken using a binomial distribution and a logit link function in Statistica 7.0 (Statsoft, Tulsa, USA) to test for effects of acclimation, pre-treatment, lifestage or interactions between these factors on survival. 
Table 1

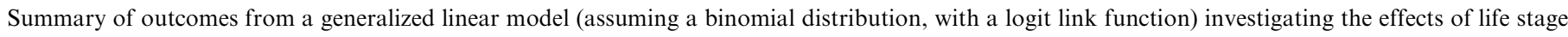
(larvae, adults), acclimation, pre-treatment and the interactions thereof on survival in Paractora dreuxi

\begin{tabular}{|c|c|c|c|c|}
\hline Effect & $\mathrm{df}$ & Log likelihood & Wald $\chi^{2}$ & $p$ \\
\hline Intercept & 1 & -442.9 & & \\
\hline Life stage & 1 & -396.4 & 93.02 & $<0.00001$ \\
\hline Acclimation & 1 & -395.0 & 2.84 & 0.0921 \\
\hline Pre-treatment & 5 & -389.7 & 10.70 & 0.0581 \\
\hline Life stage $\times$ acclimation & 1 & -389.4 & 0.66 & 0.419 \\
\hline Life stage $\times$ pre-treatment & 5 & -372.5 & 33.66 & $<0.00001$ \\
\hline Acclimation $\times$ pre-treatment & 5 & -362.0 & 21.13 & 0.0008 \\
\hline Life stage $\times$ acclimation $\times$ pre-treatment & 4 & -355.9 & 12.03 & 0.017 \\
\hline
\end{tabular}

Note that handling controls were not included in this analysis.

Subsequently, survival data were compared in a pair-wise fashion between each treatment and the control (handling) pre-treatment within each acclimation. Thus, in the case of $0{ }^{\circ} \mathrm{C}$-acclimated flies and larvae, $-4,-2,10,20,25^{\circ} \mathrm{C}$ pretreatments were compared with a $0{ }^{\circ} \mathrm{C}$ control using pairwise randomization analyses (Resampling Procedures v. 1.3 , D. Howell, University of Vermont, USA), as frequency distributions were not normal even after transformation and assumptions of equal variances were not satisfied in some treatment groups (as in Terblanche et al., 2005). Each individual pre-treatment $\left(-4,-2,0,20,25^{\circ} \mathrm{C}\right)$ for flies acclimated to $10^{\circ} \mathrm{C}$ was compared with a handling control at $10^{\circ} \mathrm{C}$ in a similar manner. A post hoc false discovery rate correction was used to correct for statistical artefacts of multiple tests on the null hypothesis (Garcia, 2004). Results are presented as proportion surviving \pm standard error of the mean (SEM) unless otherwise stated, and significance was set at $p=0.05$.

\section{Results}

Among all individuals, significant effects on survival of life stage, but not acclimation or pre-treatment were found (Table 1). In addition, significant interaction effects were detected for life stage $\times$ pre-treatment, acclimation $\times$ pretreatment, and life stage $\times$ acclimation $\times$ pre-treatment, but not for life stage $\times$ acclimation (Table 1). In other words, the nature, direction and extent of the pre-treatment effect on survival differed among life stages and among acclimation treatments.

In larvae acclimated to $0{ }^{\circ} \mathrm{C}$, low pre-treatment temperatures had no significant effect on survival while high pretreatment exposures resulted in a significant and substantial decline in survivorship (Fig. 2A). Indeed, survival declined by as much as $40 \%$ following high-temperature pre-treatments. By contrast, following acclimation to $10^{\circ} \mathrm{C}$, pre-treatments had virtually the opposite effect. Here, exposure to low, but not the lowest temperatures improved survival by more than $30 \%$, and a similar effect was found following exposure to high pre-treatment temperatures (Fig. 2A). In the adults, pre-treatments had no significant effect whatsoever (Fig. 2B). Relative to the
A

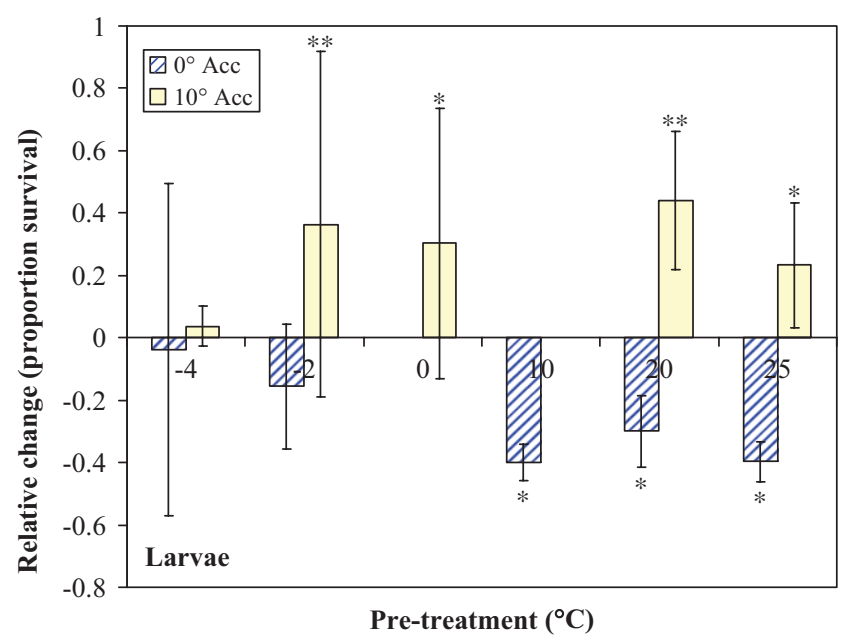

B

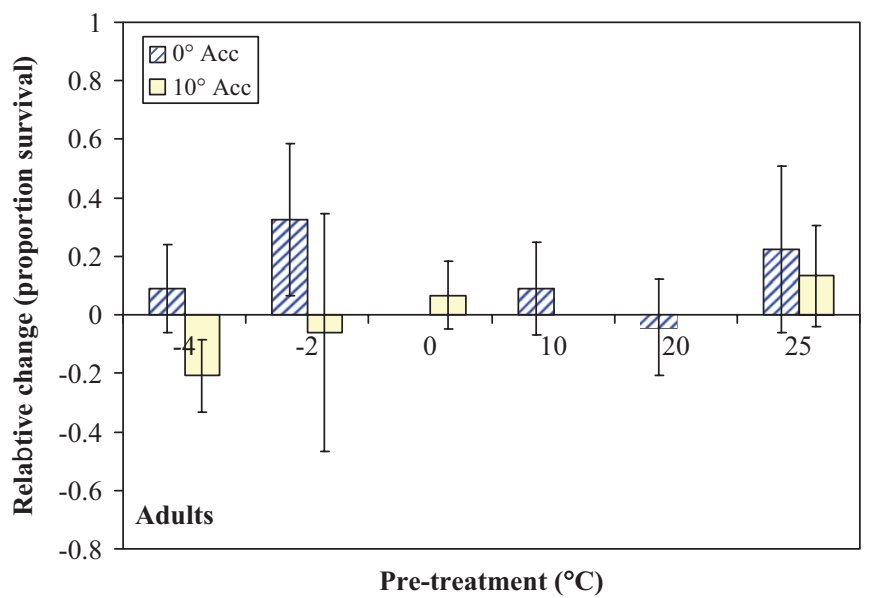

Fig. 2. Relative change in proportion survival $( \pm \mathrm{SD})$ of Paractora dreuxi (A) larvae and (B) adults after temperature pre-treatments for 0 and $10^{\circ} \mathrm{C}$ acclimation groups $(n=25-33$ per treatment). Relative survival is calculated as the handling control's survival value subtracted from the experimental treatment's survival value. ${ }^{*} p<0.05$ and ${ }^{* *} p<0.001$ after correction for multiple comparisons.

controls, adults acclimated to 0 and to $10^{\circ} \mathrm{C}$, and pretreated in a variety of ways, showed no significant increase or decline in survival. 


\section{Discussion}

The hardening responses of the larvae of $P$. dreuxi are in many ways similar to other insects. Summer-acclimated individuals show a pronounced $\mathrm{RCH}$ response, with survival increasing by $30-37 \%$. Many studies have now documented such RCH (e.g. Lee et al., 1987; Chen et al., 1990; Larsen and Lee, 1994; Klok et al., 2003; Terblanche et al., 2005; Powell and Bale, 2006) although in many cases RCH may improve the survival by $50-70 \%$ (e.g. Terblanche et al., 2005; Powell and Bale, 2006; Lee et al., 2006b). Moreover, the decline in the efficacy of the pretreatment with an increase in the stress imposed during the procedure has also been documented elsewhere (Yocum and Denlinger, 1994) and may be partly due to less individuals surviving more extreme pre-treatments, although generally the reasons for this decline are not well understood. Improved survival to a low-temperature stress following pre-treatment at a high temperature is also known from several species, including the fly Sarcophaga crassipalpis (Chen et al., 1991), Pringleophaga marioni caterpillars (Sinclair and Chown, 2003) and adults of the tenebrionid Afrinus sp. (Sinclair and Chown, 2006). What the reasons are for this cross-tolerance can only be surmised here, but in other species it has been shown that the upregulation of heat shock protein (hsp) synthesis is likely responsible (see Denlinger and Lee, 1998 a for review), although the role of specific hsp's is complex (Michaud and Denlinger, 2004). As in other studies (e.g. Sinclair and Chown, 2003, 2006) the role of hsp's in $P$. dreuxi requires confirmation, especially given more recent work demonstrating that the mechanisms underlying $\mathrm{RCH}$ may include glycerol production and alterations to fatty acid composition of membranes (Overgaard et al., 2005; Lee et al., 2006a; Yoder et al., 2006).

In the winter-acclimated larvae, the absence of a hardening response is in keeping with what might be expected of freezing-tolerant individuals (Sinclair and Chown, 2006), but contrasts strongly with the findings of Lee et al. (2006b) who documented a pronounced effect of low pre-treatment temperatures on survival of the freezing-tolerant, winter-acclimated larvae of the midge $B$. antarctica. What the ultimate reasons are for this difference are difficult to fathom, but a proximate environmental cause may be assumed: even though their winter microenvironments are buffered, B. antarctica larvae are still likely to encounter lower temperatures than are the larvae of $P$. dreuxi (cf. data in Lee et al., 2006b, p. 400 with data in Deere et al., 2006). More generally, this might account for the differences between the freezing-tolerant species on sub-Antarctic Marion Island (see also Sinclair and Chown, 2003) and B. antarctica. However, a study broader in scope, including many species from a variety of environments and which assesses phylogenetic effects, is required before any firm generalizations can be made.

By contrast, the decline in survival of winter-acclimated larvae following high-temperature treatments is not unique. found that in Sarcophaga crassipalpis, individuals rapidly decline in tolerance if exposed to a higher temperature $\left(25^{\circ} \mathrm{C}\right)$, and this seems likely to have been the case for the winter-acclimated larvae of $P$. dreuxi too. The fact that the increase in mortality was realized at a temperature as low as $10^{\circ} \mathrm{C}$ suggests that the high-temperature effect was not a consequence of multiple interacting stressors, but rather was a rapid loss of the benefits of a week-long acclimation to low temperature. To date, only a few studies have examined interactions between hardening, acclimation and longer term plastic changes to low-temperature tolerance (e.g. Chen and Walker, 1994; McDonald et al., 1997, 2000; Anderson et al., 2005; Rako and Hoffmann, 2006). It is clear from these studies that the interactions are complex, and differ among species and treatments. Therefore, comprehensive understanding thereof will require considerably greater exploration of the time by intensity response space (Chown and Terblanche, 2007).

Surprisingly, the adults showed no hardening response irrespective of the acclimation or pre-treatment conditions. Although previous investigations have shown that rapid hardening effects decline with age and differ between life stages (Czajka and Lee, 1990), complete absence of hardening is unusual. Lee et al. (2006b) found similar unresponsiveness of $B$. antarctica adults and ascribed this to their short lifespan (a few days), and to their mobility which would enable them to seek out thermally buffered microhabitats (see also Jones et al., 1987). Hawes et al. (2006) found no $\mathrm{RCH}$ in the springtail Hypogastrura tullbergi and suggested that predictably mild climates (at least for the site at which they worked) were responsible for this situation. Clearly, lifespan and the scale of environmental variation need to be taken into consideration when assessing the responses of insects to environmental variability and predictability (Palumbi, 1984; Kingsolver and Huey, 1998; Chown and Terblanche, 2007).

A lifespan of a few days is unlikely to promote the development of substantial phenotypic plasticity. However, the adults of $P$. dreuxi live for 2-3 weeks, which is sufficient for them to potentially encounter a relatively wide range of temperatures (Chown and Crafford, 1992; Deere et al., 2006). Nonetheless, over their lifespans variation in temperature is likely to be highly unpredictable, presumably also selecting against pronounced plasticity (Deere and Chown, 2006). In addition, the adults are highly mobile and might also be capable of avoiding stressful conditions by simply moving to more appropriate microclimates. The stony beaches these flies occupy comprise a complex, three-dimensional habitat, and adult flies typically make use of this complexity (Crafford, 1984; Crafford and Scholtz, 1987). Therefore, rather than use physiological means to survive low-temperature stress, they might simply regulate behaviourally (see also Jones et al., 1987). In other words, behavioural regulation may preclude selection for physiological responses (Huey et al., 2003), so explaining the lack of response in the 
adult flies to all of the experimentally imposed pretreatments.

Although larvae are mobile, they depend on the kelp substrate for food, and are much slower than the adults (Crafford, 1984), so ruling out rapid behavioural responses and movement away from the kelp wrack. Moreover, because they typically dwell within a layer of slime on the kelp, which can inoculate freezing and depress survival (Klok and Chown, 2001), a rapid response (i.e. within a few hours) to low-temperature conditions is likely essential to their survival, especially in summer. On Marion Island, cold snaps in the summer months are not infrequent (Deere and Chown, 2006). In other words, for larvae of $P$. dreuxi, predictability of conditions from day to day is less relevant than prediction of conditions from hour to hour. Thus, rather than being counter-intuitive, differences among the adults and larvae (which also include a broader thermal range in larvae than in the adults (critical thermal limits: -5.1 to $35.5^{\circ} \mathrm{C}$ vs. -2.7 to $30.2^{\circ} \mathrm{C}$, respectively), Klok and Chown, 2001) are to some extent predictable from their differences in feeding requirements and behaviour. Such physiological differences across the life cycle of holometabolous insects should be expected given the very different environments typically occupied by different life stages and even by different instars (see e.g. Casey et al., 1981, 1988; Gaston et al., 1991; Klok and Chown, 1999, see also Spicer and Gaston, 1999). Indeed, they are also commonly found in the thermal responses of insects (e.g. Morrissey and Baust, 1976; Chen et al., 1987b, 1991; Vernon and Vannier, 1996; Hart and Bale, 1997). However, given that adults and larvae of $P$. dreuxi occupy virtually the same habitat, it is clear that the way in which life-stage-related variation influences the interaction between phenotypic plasticity and environmental variability and predictability needs more thorough exploration.

In conclusion, the summer-acclimated larvae showed $\mathrm{RCH}$ whereas this was not the case in the winteracclimated larvae, so partially supporting the predictions of the predictable environments hypothesis. However, the hypothesis also predicts that the adults should have demonstrated an RCH response, yet they did not. Clearly, the original ideas set out by Sinclair and Chown (2005) were something of an oversimplification, as both this study and that of Lee et al. (2006b) have demonstrated. Nonetheless, the environmental predictability hypothesis emphasizes the need to consider environmental stochasticity during investigations of the responses of insects to low temperatures. Further development of the hypothesis will require consideration of the traits in question in the context of the lifespan of the stage being analysed, the scale of environmental predictability, and the likely influence of behavioural responses (Kingsolver and Huey, 1998; Deere and Chown, 2006; Hawes et al., 2006; Chown and Terblanche, 2007). An explicit modelling approach such as that adopted by Voituron et al. (2002) would seem to be an excellent place to start.

\section{Acknowledgements}

Erika Nortje assisted with laboratory maintenance and Jacques Deere provided valuable support at several stages in this project. Logistic support in the field was provided by the South African National Antarctic Program and the 2005/2006 take-over teams. Jacques Deere, Susana Clusella Trullas and two anonymous reviewers provided constructive comments on an earlier version of this manuscript.

\section{References}

Anderson, A.R., Hoffmann, A.A., McKechnie, SW., 2005. Response to selection for rapid chill-coma recovery in Drosophila melanogaster: physiology and life history traits. Genetical Research 85, 15-22.

Bale, J.S., 2002. Insects and low temperatures: from molecular biology to distributions and abundance. Philosophical Transactions of the Royal Society of London B 357, 849-862.

Burks, C.S., Hagstrom, D.W., 1999. Rapid cold hardening capacity in five species of coleopteran pests of stored grain. Journal of Stored Products Research 35, 65-75.

Casey, T.M., Hegel, J.R., Buser, C.R., 1981. Physiology and energetics of pre-flight warm-up in the Eastern tent caterpillar moth Malacosoma americanum. Journal of Experimental Biology 94, 119-135.

Casey, T.M., Joos, B.A., Fitzgerald, T.D., Yurlina, M.E., Young, P.A., 1988. Synchronized group foraging, thermoregulation, and growth of eastern tent caterpillars in relation to microclimate. Physiological Zoology 61, 372-377.

Chen, C.-P., Walker, V.K., 1994. Cold-shock and chilling tolerance in Drosophila. Journal of Insect Physiology 40, 661-669.

Chen, C.-P., Denlinger, D.L., Lee, R.E., 1987a. Cold-shock injury and rapid cold hardening in the flesh fly Sarcophaga crassipalpis. Physiological Zoology 60, 297-304.

Chen, C.-P., Denlinger, D.L., Lee, R.E., 1987b. Responses of nondiapausing flesh flies (Diptera: Sarcophagidae) to low rearing temperatures: developmental rate, cold tolerance, and glycerol concentrations. Annals of the Entomological Society of America 80, 790-796.

Chen, C.-P., Lee, R.E., Denlinger, D.L., 1990. A comparison of the responses of tropical and temperate flies (Diptera: Sarcophagidae) to cold and heat stress. Journal of Comparative Physiology B 160, 543-547.

Chen, C.-P., Lee, R.E., Denlinger, D.L., 1991. Cold shock and heat shock: a comparison of the protection generated by brief pre-treatment at less severe temperatures. Physiological Entomology 16, 19-26.

Chown, S.L., Crafford, J.E., 1992. Microhabitat temperatures at Marion Island $\left(46^{\circ} 54^{\prime} \mathrm{S} 37^{\circ} 45^{\prime} \mathrm{E}\right)$. South African Journal of Antarctic Research 22, 51-58.

Chown, S.L., Nicolson, S.W., 2004. Insect Physiological Ecology. Mechanisms and Patterns. Oxford University Press, Oxford.

Chown, S.L., Terblanche, J.S., 2007. Physiological diversity in insects: ecological and evolutionary contexts. Advances in Insect Physiology 33, 50-152.

Chown, S.L., Sinclair, B.J., Leinaas, H.P., Gaston, K.J., 2004. Hemispheric asymmetries in biodiversity - a serious matter for ecology. PLoS Biology 2, e406.

Crafford, J.E., 1984. Lifecycle and kelp consumption of Paractora dreuxi mirabilis (Diptera: Helcomyzidae): a primary decomposer of stranded kelp on Marion Island. South African Journal of Antarctic Research 14, 18-22.

Crafford, J.E., Scholtz, C.H., 1987. Phenology of stranded kelp degradation by the kelp fly Paractora dreuxi mirabilis (Helcomyzidae) at Marion Island. Polar Biology 7, 289-294.

Crafford, J.E., Scholtz, C.H., Chown, S.L., 1986. The insects of subAntarctic Marion and Prince Edward Islands; with a bibliography of entomology of the Kerguelen Biogeographical Province. South African Journal of Antarctic Research 16, 41-84. 
Czajka, M.C., Lee, R.E., 1990. A rapid cold-hardening response protecting against cold shock injury in Drosophila melanogaster. Journal of Experimental Biology 148, 245-254.

Danks, H.V., 2005. Key themes in the study of seasonal adaptations in insects I. Patterns of cold hardiness. Applied Entomology and Zoology 40, 199-211.

Deere, J.A., Chown, S.L., 2006. Testing the beneficial acclimation hypothesis and its alternatives for locomotor performance. American Naturalist 168, 630-644.

Deere, J.A., Sinclair, B.J., Marshall, D.J., Chown, S.L., 2006. Phenotypic plasticity of thermal tolerances in five oribatid mite species from sub-Antarctic Marion Island. Journal of Insect Physiology 52, 693-700.

Denlinger, D.L., Lee, R.E., 1998. Physiology of cold sensitivity. In: Hallman, G.J., Denlinger, D.L. (Eds.), Temperature Sensitivity in Insects and Application in Integrated Pest Management. Westview Press, Boulder, pp. 55-95.

Garcia, L.V., 2004. Escaping the Bonferroni iron claw in ecological studies. Oikos 105, 657-663.

Gaston, K.J., Reavey, D., Valladares, G.R., 1991. Changes in feeding habit as caterpillars grow. Ecological Entomology 16, 339-344.

Hart, A.J., Bale, J.S., 1997. Cold tolerance of the aphid predator Episyrphus balteatus (DeGeer) (Diptera, Syrphidae). Physiological Entomology 22, 332-338.

Hawes, T.C., Couldridge, C.E., Bale, J.S., Worland, M.R., Convey, P., 2006. Habitat temperature and the temporal scaling of cold hardening in the high Arctic collembolan, Hypogastrura tullbergi (Schäffer). Ecological Entomology 31, 450-459.

Hoffmann, A.A., Watson, M., 1993. Geographical variation in the acclimation responses of Drosophila to temperature extremes. American Naturalist 142, S93-S113.

Huey, R.B., Hertz, P.E., Sinervo, B., 2003. Behavioural drive versus behavioural inertia in evolution: a null model approach. American Naturalist 161, 357-366.

Jones, J.S., Coyne, J.A., Partridge, L., 1987. Estimation of the thermal niche of Drosophila melanogaster using a temperature-sensitive mutation. American Naturalist 130, 83-90.

Kelty, J.D., Lee, R.E., 2001. Rapid cold-hardening of Drosophila melanogaster (Diptera: Drosophilidae) during ecologically based thermoperiodic cycles. Journal of Experimental Biology 204, $1659-1666$.

Kingsolver, J.G., Huey, R.B., 1998. Evolutionary analyses of morphological and physiological plasticity in thermally variable environments. American Zoologist 38, 545-560.

Klok, C.J., Chown, S.L., 1999. Assessing the benefits of aggregation: thermal biology and water relations of anomalous Emperor Moth caterpillars. Functional Ecology 13, 417-427.

Klok, C.J., Chown, S.L., 2001. Critical thermal limits, temperature tolerance and water balance of a sub-Antarctic kelp fly, Paractora dreuxi (Diptera: Helcomyzidae). Journal of Insect Physiology 47, 95-109.

Klok, C.J., Chown, S.L., 2003. Resistance to temperature extremes in subAntarctic weevils: interspecific variation, population differentiation and acclimation. Biological Journal of the Linnean Society 78, 401-414.

Klok, C.J., Chown, S.L., Gaston, K.J., 2003. The geographical range structure of the Holly Leaf-miner. III. Cold hardiness physiology. Functional Ecology 17, 858-868.

Larsen, K.J., Lee, R.E., 1994. Cold tolerance including rapid coldhardening and inoculative freezing of fall migrant monarch butterflies in Ohio. Journal of Insect Physiology 40, 859-864.

Leather, S.R., Walters, K.F.A., Bale, J.S., 1993. The Ecology of Insect Overwintering. Cambridge University Press, Cambridge.

Lee, R.E., Chen, C.-P., Denlinger, D.L., 1987. A rapid cold hardening process in insects. Science 238, 1415-1417.

Lee, R.E., Damodaran, K., Yi, S.-X., Lorigan, G.A., 2006a. Rapid coldhardening increases membrane fluidity and cold tolerance of insect cells. Cryobiology 52, 459-463.
Lee, R.E., Elnitsky, M.A., Rinehart, J.P., Hayward, S.A.L., Sandro, L.H., Denlinger, D.L., 2006b. Rapid cold-hardening increases the freezing tolerance of the Antarctic midge Belgica antarctica. Journal of Experimental Biology 209, 399-406.

McDonald, J.R., Bale, J.S., Walters, K.F.A., 1997. Rapid cold hardening in the western flower thrips Frankliniella occidentalis. Journal of Insect Physiology 43, 759-766.

McDonald, J.R., Head, J., Bale, J.S., Walters, K.F.A., 2000. Cold tolerance, overwintering and establishment potential of Thrips palmi. Physiological Entomology 25, 159-166.

Michaud, M.R., Denlinger, D.L., 2004. Molecular modalities of insect cold survival: current understanding and future trends. International Congress Series 1275, 32-46.

Morrissey, R.E., Baust, J.G., 1976. The ontogeny of cold tolerance in the gall fly Eurosta solidagensis. Journal of Insect Physiology 22, 431-437.

Overgaard, J., Sørensen, J.G., Petersen, S.O., Loeschcke, V., Holmstrup, M., 2005. Changes in membrane lipid composition following rapid cold hardening in Drosophila melanogaster. Journal of Insect Physiology 51, 1173-1182.

Palumbi, S.R., 1984. Tactics of acclimation: morphological changes of sponges in an unpredictable environment. Science 225, 1478-1480.

Pörtner, H.O., 2001. Climate change and temperature-dependent biogeography: oxygen limitation of thermal tolerance in animals. Naturwissenschaften 88, 137-146.

Powell, S.J., Bale, J.S., 2006. Effect of long-term and rapid cold hardening on the cold torpor temperature of an aphid. Physiological Entomology 31, 348-352.

Rako, L., Hoffmann, A.A., 2006. Complexity of the cold acclimation response in Drosophila melanogaster. Journal of Insect Physiology 52, 94-104.

Rosales, A.L., Krafsur, E.S., Kim, Y., 1994. Cryobiology of the face fly and house fly (Diptera: Muscidae). Journal of Medical Entomology 31, 671-680.

Sinclair, B.J., Chown, S.L., 2003. Rapid responses to high temperature and desiccation but not to low temperature in the freeze tolerant subAntarctic caterpillar Pringleophaga marioni (Lepidoptera, Tineidae). Journal of Insect Physiology 49, 45-52.

Sinclair, B.J., Chown, S.L., 2005. Climatic variability and hemispheric differences in insect cold tolerance: support from southern Africa. Functional Ecology 19, 214-221.

Sinclair, B.J., Chown, S.L., 2006. Rapid cold-hardening in a Karoo beetle, Afrinus sp. Physiological Entomology 31, 98-101.

Sinclair, B.J., Addo-Bediako, A., Chown, S.L., 2003a. Climatic variability and the evolution of insect freeze tolerance. Biological Reviews 78, 181-195.

Sinclair, B.J., Vernon, P., Klok, C.J., Chown, S.L., 2003b. Insects at low temperatures: an ecological perspective. Trends in Ecology and Evolution 18, 257-262.

Spicer, J.I., Gaston, K.J., 1999. Physiological Diversity and its Ecological Implications. Blackwell Science, Oxford.

Terblanche, J.S., Sinclair, B.J., Klok, C.J., McFarlane, M.L., Chown, S.L., 2005. The effects of acclimation on thermal tolerance, desiccation resistance and metabolic rate in Chirodica chalcoptera (Coleoptera: Chrysomelidae). Journal of Insect Physiology 51, 1013-1023.

Terblanche, J.S., Klok, C.J., Krafsur, E.S., Chown, S.L., 2006. Phenotypic plasticity and geographic variation in thermal tolerance and water loss of the tsetse Glossina pallidipes (Diptera: Glossinidae): implications for distribution modelling. American Journal of Tropical Medicine and Hygiene 74, 786-794.

van der Laak, S., 1982. Physiological adaptations to low temperature in freezing-tolerant Phyllodecta laticollis beetles. Comparative Biochemistry and Physiology A 73, 613-620.

Vandyk, J.K., Bartholomew, D.M., Rowley, W.A., Platt, K.B., 1996. Survival of Ixodes scapularis (Acari: Ixodidae) exposed to cold. Journal of Medical Entomology 33, 6-10.

Vasseur, D.A., Yodzis, P., 2004. The color of environmental noise. Ecology 85, 1146-1152.

Vernon, P., Vannier, G., 1996. Developmental patterns of supercooling capacity in a subantarctic wingless fly. Experientia 52, 155-158. 
Voituron, Y., Mouquet, N., de Mazancourt, C., Clobert, J., 2002. To freeze or not to freeze? An evolutionary perspective on the cold-hardiness strategies of overwintering ectotherms. American Naturalist 160, 255-270.

Yocum, G.D., Denlinger, D.L., 1994. Anoxia blocks thermotolerance and the induction of rapid cold hardening in the flesh fly, Sarcophaga crassipalpis. Physiological Entomology 19, 152-158.
Yoder, J.A., Benoit, J.B., Denlinger, D.L., Rivers, D.B., 2006. Stressinduced accumulation of glycerol in the flesh fly, Sarcophaga bullata: evidence indicating anti-desiccant and cryoprotectant functions of this polyol and a role for the brain in coordinating the response. Journal of Insect Physiology 52, 202-214.

Zachariassen, K.E., 1985. Physiology of cold tolerance in insects. Physiological Reviews 65, 799-832. 